\title{
ОСОБЕННОСТИ РАЗВИТИЯ КОПИНГ-СТРАТЕГИЙ У ПОДРОСТКОВ С РАЗНЫМ УРОВНЕМ СКЛОННОСТИ К АДДИКТИВНОМУ ПОВЕДЕНИЮ
}

\section{FEATURES OF THE DEVELOPMENT OF COPING STRATEGIES IN ADOLESCENTS WITH DIFFERENT LEVELS OF PROPENSITY FOR ADDICTIVE BEHAVIOR}

S. Mast

Summary: The article examines the psychological and pedagogical conditions for the development of effective coping strategies in adolescents with different levels of propensity for addictive behavior. Purpose of the study: to study the specifics of adolescent addictive behavior in order to substantiate a complex of preventive and correctionaldevelopmental measures for the development of productive coping strategies. The structural and content characteristics of coping strategies of adolescents with high and low levels of propensity to addictive behavior are considered. The directions of development of productive coping strategies in the behavior of adolescents are concretized.

Keywords: adolescent, coping strategy, addictive behavior, psychological and pedagogical prevention, the level of propensity to addictive behavior.
Маст Светлана Викторовна Клинический психолог, аспирант, ГАОУ ВО Ленинградской области «Ленинградский государственный университет имени А.С. Пушкина», г. Санкт Петербург Svetlanamast@mail.ru

Аннотация: В статье рассмотрены психолого-педагогические условия развития эффективных стратегий совладающего поведения у подростков с разным уровнем склонности к аддиктивному поведению. Цель исследования: изучить специфику аддиктивного поведения подростков для обоснования комплекса профилактических и коррекционно-развивающих мероприятий по выработке продуктивных копинг-стратегий. Рассмотрены структурно-содержательные характеристики копинг-стратегий подростков с высоким и низким уровнем склонности к аддиктивному поведению. Конкретизированы направления развития продуктивных копинг-стратегий в поведении подростков.

Ключевые слова: подросток, копинг-стратегия, аддиктивное поведение, психолого-педагогическая профилактика, уровень склонности к аддиктивному поведению.
B современный исторический период социальная среда предъявляет ряд требований к компетенциям и личностным ресурсам подрастающего поколения, выдвигая среди наиболее востребованных, такие как: стрессоустойчивость, способности самостоятельно справляться с проблемами, конструктивно решать конфликты и ассертивно взаимодействовать в конфронтации с людьми. Все эти качества лежат в основе выбираемых форм совладающего поведения (копинг-стратегий). Их развитию способствует ряд факторов и средств социализации, в частности, влияние семьи, воспитание в образовательном учреждении, самовоспитание. В зависимости от психолого-педагогических условий, целенаправленного или стихийного характера развития личности, количества и специфики трудных, стрессогенных ситуаций у подростков формируются продуктивные или непродуктивные формы совладающего поведения. Актуальность развития продуктивных копинг-стратегий возрастает в подростковом возрасте, т.к. он является периодом кризиса, отчуждения от взрослых, поиска автономии и новых форм взаимодействия. В это время высока вероятность аддиктивного поведения как некого средства «ухода» от стрессов, конфликтов и удовлетворения определенных потребностей подростка.
Пытаясь уйти от контроля родителей, репрезентуя «чувство взрослости», но, не имея достаточных личностных ресурсов и социальных навыков решения проблем, подросток может выбирать неэффективные формы копинга: растерянность, избегание, агрессивность и т.д. Значимость проблемы развития продуктивных копинг-стратегий возрастает в ситуации с подростками, оставленными без попечения родителей и воспитывающихся в замещающих семьях. В связи с недостаточной степенью социализации у такой группы детей отсутствует «модель и опыт эффективного совладания с трудными жизненными ситуациями». [2]

Поэтому, мы считаем важным изучение специфики копинг-стратегий у подростков из кровных семей в сравнении с подростками из замещающих семей (с разным уровнем склонности к аддиктивному поведению). Данное исследование позволяет выявить особенности совладающего поведения подростков в зависимости от условий социализации, выбираемые ими копинг-стратегии и степень их эффективности. Такие фактические данные помогут конкретизировать направления профилактической и психолого-педагогической работы с группами подростков с разным уровнем склонности к 
аддикции.

В качестве теоретико-методологической базы исследования мы рассмотрели научные труды отечественных и зарубежных психологов по проблеме развития копинг-стратегий в зависимости от уровня склонности к аддиктивному поведению личности. В частности, среди основных направлений исследований нами выделены следующие:

1. Исследование сущности копинг-ресурсов личности, обеспечивающие успешность поведения, совладающего со стрессом (В.А. Абабков, О.С.Ахмедова,Л.И.Вассерман,Р.Лазарус,С.А.Хазова, Б.Д. Карвасарский, Н.Ф. Михайлова и другие).

2. Исследование копинг-стратегий в рамках теории деятельности, представленную в трудах отечественных ученых (В.И. Абабков, Л.И. Анцыферова, А.В. Кибальник, Леонтьев Д.А.) и, объединяющей психологическую защиту и совладающее поведение в единый феномен защитно-совладающего поведения.

3. Исследование закономерностей развития аддиктивного поведения личности (А.Ю. Акопов, Е.В. Змановская, И.С. Кон и другие).

Для того чтобы определиться с направлениями развития продуктивных стратегий совладающего поведения подростков, рассмотрим сущностные характеристики данного теоретического конструкта. Понятие «копинг-стратегий» используется в контексте проблем, описывающих стили реагирования личности, ее защитные механизмы и способы решения трудностей. В данном случае «копинг - это совладание с возникшим стрессом, адаптивный способ поведения для гомеостаза».[7] Изначально совладающее поведение рассматривалось как психологический защитный механизм, позволяющий человеку избавиться от тревоги и разочарований. В таблице 1 представлены критерии разграничения понятий «копинг» и «защита», которые показывают их существенные различия.

Таблица 1.

Сопоставление понятий «защита» и «копинг»

\begin{tabular}{|l|l|}
\hline Психологическая защита & Копинг \\
\hline $\begin{array}{l}\text { Бессознательность осуществления } \\
\text { защит }\end{array}$ & $\begin{array}{l}\text { Сознательность использования } \\
\text { стратегии поведения }\end{array}$ \\
\hline Искажение реальности & Ориентированность на реальность \\
\hline Ориентация на себя & $\begin{array}{l}\text { Ориентация и на себя, и на со- } \\
\text { циальное окружение }\end{array}$ \\
\hline $\begin{array}{l}\text { Регулирование с помощью по- } \\
\text { давления и ухода }\end{array}$ & $\begin{array}{l}\text { Регулирование с помощью рефлек- } \\
\text { сии, непосредственных действий }\end{array}$ \\
\hline $\begin{array}{l}\text { Цель: снижение тревоги путем вы- } \\
\text { теснения тревожащей информа- } \\
\text { ции, маскировка недееспособности }\end{array}$ & $\begin{array}{l}\text { Цель: активное преобразование } \\
\text { эмоциональных состояний в соот- } \\
\text { ветствии с актуальной ситуацией. }\end{array}$ \\
\hline
\end{tabular}

Исходя из данных таблицы, копинг-стратегии, являясь сознательно регулируемым поведением, требуют от личности использования всех ресурсов: эмоциональных, поведенческих и когнитивных, обеспечивая более пластичный подход в адаптации. В рамках нашего исследования, ключевую роль в определении методологических основ, представляет концепция Р. Лазаруса. (R.S. Lazarus), в соответствии с которой под «копингом» понимается «стремление к разрешению проблем, которое проявляется, когда индивид находиться в ситуациях угрозы либо успеха для него, при имеющихся условиях для активизации его адаптивных возможностей целью которых является, сохранение физиологического, индивидуального и социального благополучия». [9] Ученым была разработана трехфакторная модель копингмеханизмов, к которым ученый относит 3 компонента: копинг-ресурсы, копинг-стратегии и копинг-поведение. В нашем исследовании, в качестве основного мы будем рассматривать определение копинг-поведения, представленное в трудах С.А. Хазовой, «социальное поведение или комплекс осознанных адаптивных действий (когнитивных), аффективных, поведенческих, помогающих человеку справляться с внутренним напряжением и дискомфортом способами, адекватными личностным особенностям и ситуации через осознанные стратегии действий» [8, С. 60]. Теоретические положения копингповедения учитываются нами в исследовании проблем аддиктивного поведения детей-сирот и детей, оставшихся без попечения родителей, и имеют важное значение для разработки личностных копинг-ресурсов. В ряде проведенных нами исследований (в период с 2015- по 2019 г.) $[4,5]$ мы рассмотрели взаимосвязь выбираемых копинг-стратегий подростков с уровнем их склонности к аддиктивному поведению. Для проведения эксперимента мы сформировали три группы подростков: 1) экспериментальная - выборка испытуемых, воспитывающихся в замещающих семьях и имеющих высокий уровень склонности к аддиктивному поведению; 2) 1 контрольная -подростки, воспитывающиеся в замещающих семьях с низким уровнем склонности к аддикции; 3) 2 контрольная группа - -подростки, воспитывающиеся в кровных семьях с низким уровнем склонности к аддикции. На рисунке 1 приведены показатели копинг-стратегий для исследуемых групп подростков, полученные на констатирующем этапе эксперимента с помощью методики диагностики копинг-стратегий Э. Хайма.

Данные диаграммы показывают нам, что чем выше склонность к аддиктивному поведению, тем ниже уровень социальной адаптированности, стрессоустойчивости и выше вероятность выбора неэффективных форм совладающего поведения. Следовательно, в экспериментальной группе мы видим преобладание непродуктивных форм копинг-стратегий, наряду с относительно продуктивными. Самые высокие показатели склонности к продуктивным формам совладания выявлены у под- 
Таблица 2.

Качественно-содержательный анализ копинг-стратегий

\begin{tabular}{|l|c|c|c|c|c|c|c|c|c|}
\multirow{2}{*}{\multicolumn{1}{c|}{ Группа }} & \multicolumn{3}{|c|}{ Когнитивные стратегии(\%) } & \multicolumn{2}{c|}{ Эмоциональные стратегии (\%) } & \multicolumn{3}{c|}{ Поведенческие стратегии(\%) } \\
\cline { 2 - 12 } & $+*$ & $+/-$ & - & + & $+/-$ & - & + & $+/-$ & - \\
\hline Экспериментальная & - & $58,3 \%$ & $41,7 \%$ & - & 11,4 & 88,9 & - & 69,4 & 36,6 \\
\hline 1 контрольная & 20,6 & 41,2 & 38,2 & 32,4 & 11,8 & 55,9 & 14,7 & 64,7 & 20,6 \\
\hline 2 контрольная & 8,6 & 60 & 31,1 & 37,1 & 34,4 & 28,6 & 866 & 71,4 & 20 \\
\hline
\end{tabular}

*В таблице приняты сокращения: «+» - продуктивные копинг-стратегии, «+/» -относительно продуктивные; «-« - непродуктивные.

ростков, воспитывающихся в кровных семьях. Для выбора направлений психокорреционного воздействия мы провели качественно-содержательный анализ копинг-стратегий по содержащимся в них когнитивных, поведенческих, эмоциональных составляющих. Данные приведены в таблице 2.

Качественный анализ позволил выявить, что в экспериментальной группе выбирают в качестве преобладающих: 1) когнитивных стратегий: непродуктивные - растерянность и смирение; 2) эмоциональных: непродуктивные -подавление эмоций и агрессивность; 3) поведенческих: непродуктивные и относительно продуктивные - компенсация, активное избегание. При этом «растерянность» преобладает в качестве основной поведенческой копинг-стратегии у большинства подростков, что подтверждает факт их недостаточной компетентности в разрешении проблем, незнании собственных возможностей и личностных ресурсов в ситуации совладания. «Подавление эмоций» как стратегия также доминирует в эмоциональных формах совладания со стрессом. Путем ухода в себя подросток пытается отключиться от требований реальности, что способствует развитию мотивации избегания неудачи, недостаточной открытости и обращенности в мир. Это подтверждают и доминирующие поведенческие копинг-реакции: «Активное избегание» и «Компенсация». Эти формы совладающего поведения также подкрепляют разные виды зависимости в жизни подростка, как способа отвлечься, избегая трудных ситуаций и стресса.

Мы можем сделать вывод о том, что в эмоциональном плане подростки со склонностью к аддиктивному поведению (экспериментальная группа) предпочитают использовать непродуктивные копинг-стратегии, связанные с подавлением эмоций, либо неконструктивной эмоциональной разрядкой. [3] Такие дети не имеют развитых навыков открытого взаимодействия, конструктивной активности и сотрудничества для саморегуляции и преодоления сложных ситуаций более «экологичным» способом для себя и окружающих. Для подростков с низким уровнем склонности к аддиктивному поведению (1 и 2 экспериментальные группы) характерны: более стабильное эмоциональное состояние, копинг-стратегии с преобладанием относительно продуктивных и продуктивных.

Данные исследования подтверждают научное предположение о том, что развитие продуктивных копингстратегий будет благоприятно влиять и на коррекцию аддиктивных форм поведения у подростков. Выявленные содержательные характеристики эмоциональных, когнитивных и поведенческих копинг-стратегий позволяют сформулировать направления развития продуктивных форм совладающего поведения в подростковом возрасте:

1. Развитие личностных копинг-ресурсов: повышение самооценки, уровня эмпатии, навыков эмоциональной регуляции (в том числе снижение уровня тревожности), развитие мотивации достижения успеха, коммуникативных навыков.

2. Формирование эффективных поведенческих стратегий, направленных на сотрудничество; эмоциональных: оптимизма, управления эмоциями, кооперации; когнитивных: связанных с навыками проблемного анализа ситуаций в противовес к растерянности, смирению и игнорированию.

В рамках профилактической работы с подростками нами была разработана и апробирована программа «Новый путь», в содержание которой были заложены целевые ориентиры обозначенных выше направлений. K основным задачам программы относятся: развитие рефлексивной позиции подростка и навыков эффективной коммуникации; становление комплекса умений саморегуляции, навыков планирования и реализации целей; повышение осведомленности подростков и родителей о действии и последствиях аддикции. В качестве основных форм коррекционно-развивающей работы мы выбрали: тренинги с элементами арт-, драма-, и сказкотерапии, а также дискуссии, лектории и беседы. Кратко охарактеризуем направления реализации программы по содержательным блокам:

1. Мотивационный блок (6 занятий), цель которого формирование эффективного взаимодействия на основе норм групповой работы, эффективных коммуникативных навыков. 
2. Личностный блок (6 занятий), направленный на формирование рефлексивной позиции подростка на основе расширения представлений о собственном внутреннем мире, эмоциональных переживаниях человека, ценностных основах мотивации и т.Д.

3. Коммуникативный блок (10 занятий), нацеленный на ознакомление с миром межличностной коммуникации и взаимодействия, ролью доверительных контактов; на понимание значения дружеских отношений на основе толерантности. В рамках одного из важнейших направлений работы, подростки знакомятся со способами ассертивного поведения, преодоления проблемных ситуаций посредством данных стратегий.

4. Блок саморегуляции (6 занятий), целью которого является формирования навыков эффективного преодоления стресса, расширение представлений о способах эмоциональной регуляции и личностных качествах стрессоустойчивости.

5. Блок целеполагания и планирования (3 занятия), реализующий себя через сформированные компетенции постановки целей, планинга, а также понимания эффективных взаимоотношений в семье.

Помимо комплекса занятий в рамках пяти представленных выше блоков, мы реализовали ряд куль- турно-досуговых и социально-значимых мероприятий, ориентированных на развитие продуктивных стратегий поведения подростков, осознание роли позитивного общения и получения опыта деятельности, приносящей удовольствие (как альтернативы аддиктивному поведению). Участие в акциях волонтерской деятельности, спортивных соревнованиях и мастер-классах способствовало расширению ресурсного потенциала подростков. Особое внимание в рамках реализации профилактических мероприятий мы уделили работе с родителями в замещающей семье. С целью повышения их педагогической компетентности в воспитании детей-сирот, мы разработали подпрограмму «Шаг навстречу». Задачами работы явилось развитие рефлексивной позиции родителей, расширение системы знаний о подростке со склонностью к аддикции, становление ресурсов семьи и создание в ней развивающей среды.

В заключение отметим, что профилактическая и психокоррекционная работа с подростками, воспитывающимися в замещающих семьях и склонных к аддикциям, должна быть сконцентрирована на становлении адаптивных, активных и конструктивных копинг-стратегий, а основными задачами должны стать: развитие личностно-средовых копинг-ресурсов, функциональных копингстратегий и адаптивного, функционального поведения.

\section{ЛИТЕРАТУРА}

1. Дементий, Л.И. К проблеме диагностики социального контекста и стратегий копинг-поведения// Журнал прикладной психологии. - 2004. - № 3. - С. $20-25$.

2. Дружинина, Ю.А. Особенности совладающего поведения в подростковом возрасте // ОНВ. 2012. №5 (112). - С.172-175.

3. Кибальник, А.В. Психолого-педагогические особенности младших подростков, склонных к аддиктивному поведению / А.В. Кибальник, И.В. Федосова // Казанский педагогический журнал. - 2019. - №2, С. 87-91.

4. Маст, С.В. Личностные копинг-ресурсы подростков, проживающих в замещающих и кровных семьях// Сибирский педагогический журнал/ ФГБоу в0 Новосибирский государственный педагогический университет. - Новосибирск, -2018. - №3. -С. 99-107.

5. Маст, С.В. Аддиктивное поведение детей-сирот и детей, оставшихся без попечения родителей, как особая форма девиации// Специальное образование: научно-методический журнал/ ФГБОУ ВО «Урал. гос. пед. ун-т». Ин-т спец. образования. - Екатеринбург, 2017. - №4 (48). - С.117-128.

6. Самойлина, Т.Г., Михайлюк Е.Б. Психокоррекция и психопрофилактика девиаций с учетом особенностей защитно-совладающего поведения подростков// Северо-Кавказский психологический вестник. 2009. №4.

7. Симатова, 0.Б. Теория копинг-поведения как основа первичной психолого-педагогической профилактики аддиктивного поведения подростков // Вестник ЗабГУ. 2009. №6. - С. 95-98.

8. Хазова, С.А. Когнитивные ресурсы совладающего поведения: эмпирические исследования. М-во образования и науки Российской Федерации, Костромской гос. ун-т им. Н.А. Некрасова. - Кострома: КГУ, 2010. - 149 с.

9. Lasarus R.S. The Concept of Coping / R.S. Lasarus, S. Folkman // Stress and Coping: an anthology. N.Y.: Columbia University Press. - 1991. - P. 189-206.

(c) Маст Светлана Викторовна (Svetlanamast@mail.ru). 